\title{
Using Converging Strategies to Reduce Divergence in Intercultural User Interface Design
}

\author{
Rüdiger Heimgärtner \\ Research \&Development, Intercultural User Interface Consulting (IUIC), Undorf, Germany \\ Email: ruediger.heimgaertner@iuic.de
}

How to cite this paper: Heimgärtner, R. (2017) Using Converging Strategies to Reduce Divergence in Intercultural User Interface Design. Journal of Computer and Communications, 5, 84-115. https://doi.org/10.4236/jcc.2017.54006

Received: January 5, 2017

Accepted: March 11, 2017

Published: March 14, 2017

Copyright $\odot 2017$ by author and Scientific Research Publishing Inc. This work is licensed under the Creative Commons Attribution International License (CC BY 4.0).

http://creativecommons.org/licenses/by/4.0/ (c) (i) Open Access

\begin{abstract}
This chapter starts with an introduction illuminating the theoretical background necessary for taking culture into account in HCI design. Definitions of concepts used are provided followed by a historical overview on taking culture into account in HCI design. Subsequently, a glimpse of the current state of research in culture-centered HCI design is derived from secondary literature providing the gist of the structures, processes, methods, models and theoretic approaches concerning the relationship between culture and HCI design ("converging" strategies). After presenting controversies and challenges, a short discussion of results from empirical studies and design recommendations for culture-centered HCI design lead to implications and trends in future intercultural user interface design research to close the knowledge gap (the "divergence") regarding the relationship between culture and Human-Computer Interaction (HCI), i.e. converging the divergence to reach the convergent divergence.
\end{abstract}

\section{Keywords}

Culture, HCI, Cross-Cultural, Design, Intercultural, Culture-Centered, Methods, Tools, Standards, Overview, State of Research, Cultural Differences, Communication, Understanding, Empathy, Intercultural Communication, Intercultural HCI Design, Divergence, Convergence, Wave, Process, Cycle

\section{Introduction and Problem Discussion}

It's a natural result of the media convergence we've seen happening for decades, that companies are now starting to converge to offer a new model and to enjoy the same benefits. Therefore, also in intercultural user interface design (IUID), it is reasonable to look for ideas that are deeply connected to culture, which can 
align with societal changes and can help to stay lean, focused and as profitable as possible without compromising on quality. Cultures are melting together permanently-implicitly e.g. by the process of globalization and explicitly e.g. by doing IUID. Divergence in IUID is represented by the different perspectives in applying IUID concerning objectives, strategies and processing including processes, methods, and tools. This divergence in IUID is reduced to the extent cultures converging implicitly and converging strategies in IUID are applied explicitly.

\section{Relationship between Convergence and Divergence in Intercultural User Interface Design and Related Problems}

Up to know, there is still a remarkable knowledge gap (a divergence) regarding the relationship between culture and Human-Computer Interaction (HCI). This gap as well as the gap between developer and other culturally imprinted endusers (i.e. another-different-divergence) must be closed by using "converging" strategies that should ensure to yield successful intercultural user interface design (IUID). Today, such strategies contain at least the method of culture oriented HCI design applying intercultural variables (cf. [1]), user interface characteristics (cf. [2]), and intercultural usability engineering (cf. [3]) as well as using HCI dimensions (cf. [4]). These approaches are used to support the design process which finally should lead to good user interfaces of high usability provoking excellent user experience. However, the successful application of these approaches strongly depends on the successful intercultural communication which again depends on the personal ability to mutually understand the web of belief of the others using empathic capabilities (cf. [5]). Experienced designers are aware of this. Young designers have to acquire the experience first. Thereby, several "waves" of diverging and converging emerge, gathering knowledge (converging) and distributing knowledge (diverging). These kinds of ups (converging) and downs (diverging) in processes can be determined also in the overall perspective of designing HCI for the world. Localization (divergence) led to internationalization and UI4All (user interfaces for all) (convergence), which in turn recently dissolved again in indigenous perspectives and designed for the wild (divergence) (cf. [6]). In addition, this can be observed in the wavelike behavior within the HCI design process from top (abstract-convergence) to the bottom (concrete-divergence) and vice versa, which is iterative design, i.e. traversing the phases in circles. In this chapter, the mentioned "waves of divergence and convergence" in this sense are elucidated in detail in the cultural context to derive implications and recommendation for adapting; optimizing and possibly extending (e.g. by using universals (cf. [7])) the existing "converging" strategies in the field of intercultural user interface design.

\section{Method: Literature State of the Art/Literature Review}

To capture the paradigms and newest aspects regarding methodology, technology transfer and the diffusion of innovation, one has to browse through the lite- 
rature up to now to get an impression about what the most important tasks in intercultural HCI research can, should or must be in the future. The publications compiled by the author within this field of research connecting culture and HCI serve to determine the current state of research in this area and to categorize the main research topics in culture-centered HCI design. The most prominent results of this collection process by the author are presented in the following.

\subsection{Terminology}

There are several concepts of "culture". According to the cultural anthropologist Edward T. Hall, culture co-occurs with communication. Culture is a "silent language" or "hidden dimension" which steers people unconsciously (cf. [8]). Difficulties in communication with members of other cultures arise from that. If one is not conscious of one's own motives, which are culturally influenced, one cannot understand the motives and actions of others (cf. [5]). The position that is taken in this paper is that culture is a set of facts (structural conditions) representing an orientation system established by collective programming of the mind (cf. [9]) within a group of individuals. Cultural models describe the cultural distance, i.e. the differences between cultures and allow the comparison of them with each other (cf. [10]). One of the best-known cultural models is the iceberg model of culture (cf. [11]). Only $10 \%$ of the attributes of a culture are visible and conscious. The rest is invisible and unconscious and hence, difficult to investigate. Cultural models help to overcome this methodological gap using cultural standards and dimensions to look beneath the water surface, i.e. to probe the unconscious areas of culture. The organizational psychologist Alexander Thomas established the concept of "cultural standards", which expresses the normal, typical and valid attributes for the majority of the members of a certain culture regarding the respective kinds of perception, thought, judgment and action (cf. [12]): 112). Cultural standards serve as an orientation system for the members of a group and regulate action. The individual grows into its culture by assuming and internalizing these cultural standards. This process encompasses learning basic human abilities in the social arena, control of one's own behavior and emotions, the satisfaction of basic needs, worldview, verbal and nonverbal communication and expectations of others as well as the understanding of one's role and scales for judgment. Another key concept for describing a cultural system is that of "cultural dimension", which can serve as a basis for the identification of cultural standards (cf. [13]: 38). According to Hofstede, cultural dimensions are quantitative models to describe the behavior of the members of different cultures allowing the analysis and comparison of the characteristics of different groups quantitatively (cf. [9]) because the cultural imprint of cultural groups can be measured using quantitative questionnaires (cf. [14]). This should also be done for all other cultural dimensions. They represent an aspect of a culture, which is measurable in relation to other cultures. Hence, cultural dimensions can be used to classify kinds of behavior between cultures. Cultural dimensions are indicators showing tendencies in the interaction and communication behavior of members of cultures. 
There are similar concepts taking cultural aspects in HCI design into account. At least the following concepts exist:

- Intercultural HCI design [3] [15] [16] [17].

- Cross-cultural HCI design [18] [19].

- Culture-oriented HCI design [1].

- Culture-centered HCI design [20].

Their connotations are different, which predisposes the concepts to be applied differently in diverse contexts. Intercultural HCI design means the process of HCI design in the cultural context (cf. [21]). Intercultural HCI design describes the user and culture oriented design of interactive systems and products taking the cultural context of the user into account with respect to the respective tasks and product usage (cf. [1] [22]). This approach has grown in academic literature from 1990 to 2000 and emerged from the processes of globalization, internationalization and localization of products. Localization (L10N) means the adaptation of the system to certain cultural circumstances for a certain local market, for example the adaptation of the look and feel of the user interface or the internal data structures to the cultural needs of the user (cf. [23]). Internationalization (I18N) of a product means that the product will be prepared for its usage in the desired (in the best case for all) countries (cf. [24]). The internationalization of a software product delivers a basic structure on which a later cultural customization (localization) can be carried out. Globalization (G11N) encompasses all activities with regard to the marketing of a (software) product outside a national market (including I18N and L10N software). The objective is to run successful marketing in one or several regional markets by taking into account the technical, economic and legal conditions there [25]. Marcus requested additionally that cross-cultural HCI design should account for dimensions of cultures relating them to user interface characteristics (cf. [18]). Several researchers established the culture-centered HCI design process on research on cross-cultural interface design (cf. [1] [20] [26]) and thereby applying iterative analysis to take the target users and their cultural needs into account. Therefore, the topic of intercultural $\mathrm{HCI}$ analysis is particularly interesting from the information sciences point of view since this can yield new knowledge, new requirements and goals for the design of information processing systems involving software engineering, software ergonomics and usability engineering.

\subsection{History}

"Intercultural research in Information Systems is a relatively new research area that has gained increasing importance over the last few years [...]" ([27]: 17). Using the key words "cross-cultural HCI" when searching the ACM digital library reveals an exponential rise of publications in this area since 2000 (cf. Figure 1).

There are several papers in the literature review concerning the usage of information systems in their cultural context. Two of the first important books regarding internationalization of HMI are "Designing User Interfaces for International Use" [28] and "International User Interfaces" [29]. Another very good in- 
Searching "cross-cultural HCl" in the digital library of ACM

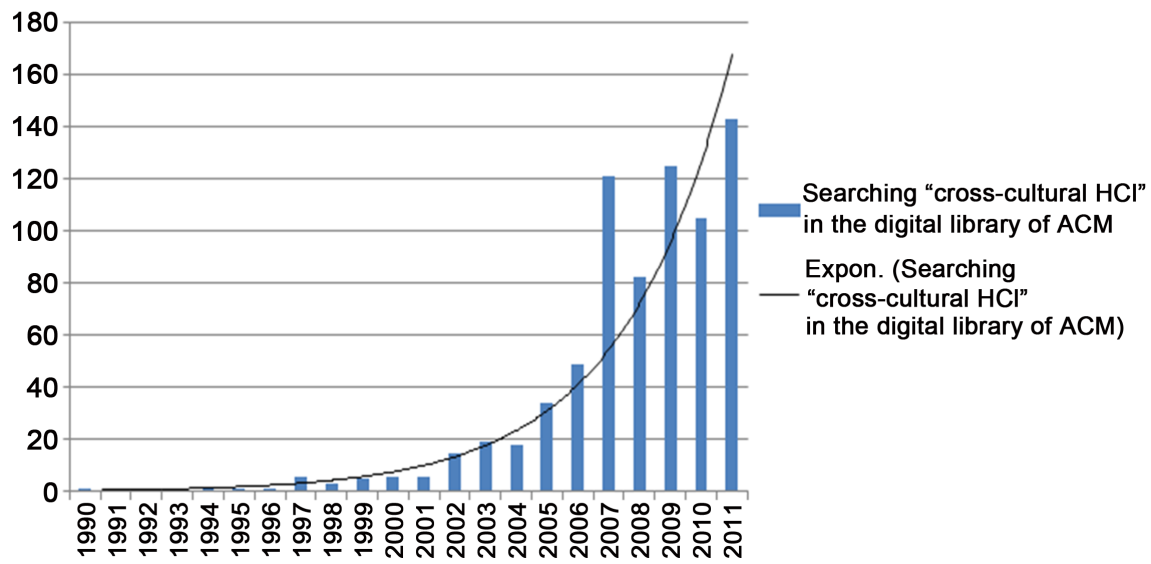

Figure 1. Approximating exponential rise of publications regarding cross-cultural HCI design in the ACM digital library.

troduction to the study of cross-cultural of $\mathrm{HCI}$ is [30] reviewing the research methodology, the technology transfer and the diffusion of innovation to shed light on the cross-cultural study of human-computer interaction. Another overview of culture and its effects on HCI is given in [31]. There is also activity investigating the trends in intercultural HCI (cf. [32]). A review of culture in information systems research to postulate a shift to a theory of information technology culture conflict is presented in [33]. The relationship between culture and computers can be illuminated by a re-view of the concept of culture and implications for intercultural collaborative online learning [34]. An overview of a decade of journal publications about culture and HCI can be found in [35].

From this, several "hypes" can be identified in this area. The first one happened in the early 1990ies. The next one was around 2000 and since about 2010 research in intercultural HCI design has steadily increased. In these "hypes" the number of publications is high indicating high research interest and effort:

- Before 1990: almost no publications available relating "culture" and "HCI".

- 1990-1999: pioneers [11] [29] [36] [37].

- 2000-2004: basic systematic work [1] [3] [18] [38] [39] [40] [41].

- 2005-2010: evaluating the new field and the systematic work [20] [42] [43] [44] [45].

- Since 2010: strongly driving research in this field [17] [46] [47] [48] [49].

Another kind of categorization of the field represents the TLCC model which was derived from the analysis of the history of examining the cultural aspects in HCI design and contains four levels of depth and thereby takes cultural aspects in HCI design into account [50]. This model shows the historical growth of internationalization and localization steps in $\mathrm{HCI}$ design represented by its four levels: technical affairs (T), language (L), culture (C) and cognition (C). At the lowest level, certainly adequate programming languages, representation forms and character sets (Unicode), etc. must be used (cf. [51]). Technical aspects have to be adapted so that the products can be used in every country (for example, 
power supply). Adapting software to Unicode is an example of a precondition to process Asian languages at the language level. Adaptation at cultural level concerns country-specific aspects including format, currency, colors, modality, menu structure, content of the menu, help, number of messages, length of texts, number of hints, degree of entertainment or ratio of information to entertainment. At the highest level, cognitive styles that describe types of human thinking such as problem solving or making conclusions can be taken into account (cf. [52] [53]). These processes strongly effect not only the functionality and the user interface of the product (i.e., monitor, keyboard, soft and hard keys, control buttons, speech dialogs, within a graphical (GUI) or speech (SUI) user interface, etc.) but also interactive behavior. In cross-cultural HCI design cultural and cognitive aspects must be taken into account in addition to technical and linguistic aspects of localization, in any case. However, in industry, the usage of internationalization concepts beyond the technological and language level has only recently been initiated (cf. e.g., [54] [55]). Thereby, it has been suggested how to cross-culturally implement information systems [56]. Today, in industry at least technical and linguistic aspects are taken into account in designing products for other cultures. In contrast, the academic approach is predominately concerned with cultural and cognitive aspects.

\section{Results: Methodologies \& Approaches for Converging Divergences in Intercultural User Interface Design}

To bridge the divergence represented by the gap in the knowledge of the differences in intercultural HCI design, converging methods and approaches to reduce this divergence are presented in the following.

\subsection{Intercultural Variables and Method of Culture-Centered Design}

Intercultural variables describe the differences in HCI design regarding the preferences of the users of different cultures [22]. "Intercultural" variables represent knowledge that can be obtained only by observing at least two cultures and their differences, i.e. doing intercultural research (cf. [57]) to obtain relevant knowledge for internationalization of software and system platforms (cf. Table 1).

Hence, "intercultural variables" are referred to in cases where the intercultural research character for obtaining the values of the variables is meant and "cultural variables" are denoted, when mainly the usage of the values of the variables themselves (concerning a specific culture) is important. However, they can also be called simply "cultural" variables, because the values of those variables represent knowledge for a specific culture (relevant for system and software localization). There are "direct" and "indirect" cultural variables affecting HCI parameters either directly (e.g., interaction, information presentation or language) or indirectly (e.g., via maintenance, documentation or technical surroundings). Direct cultural variables are the most important, because they have direct and essential influence on the design of HCI. Direct variables can be divided into 
Table 1. Intercultural variables according to [22]: 97 et. seqq. (estimated values regarding the difficulty to recognize the variables are added by the author).

\begin{tabular}{ccccc}
\hline $\begin{array}{c}\text { Intercultural } \\
\text { variable }\end{array}$ & $\begin{array}{c}\text { Level of } \\
\text { localization }\end{array}$ & $\begin{array}{c}\text { Relation to } \\
\text { HCI design }\end{array}$ & $\begin{array}{c}\text { Perceivability } \\
\text { of the variables }\end{array}$ & $\begin{array}{c}\text { Estimated } \\
\text { difficulty to } \\
\text { recognize } \\
\text { [0 (easy) - 10 } \\
\text { (difficult) }\end{array}$ \\
\hline $\begin{array}{c}\text { Dialog design } \\
\text { Interaction } \\
\text { design }\end{array}$ & Interaction & Direct & $\begin{array}{c}\text { Hidden/Over long time } \\
\text { and deep analysis }\end{array}$ & 10 \\
$\begin{array}{c}\text { System } \\
\text { functionality }\end{array}$ & Function & Indirect & $\begin{array}{c}\text { Hidden/Over long time } \\
\text { and deep analysis }\end{array}$ & 9 \\
$\begin{array}{c}\text { Service } \\
\text { Vaintenance) }\end{array}$ & Function & Indirect & Visible/Immediately & 7 \\
$\begin{array}{c}\text { Technical } \\
\text { documentation } \\
\text { Information } \\
\text { presentation }\end{array}$ & Function & Indirect & Visible/Immediately & 8 \\
Language & Surface & Direct & Visible/Immediately & 4 \\
$\begin{array}{c}\text { General system } \\
\text { design }\end{array}$ & Surface & Indirect & Visible/Immediately & 0 \\
\hline
\end{tabular}

"visible" variables concerning surface levels and "hidden" variables affecting interaction levels, together mirroring the concept of the iceberg metaphor [22]. Both kinds of variables have strong influences on the design and determination of the usability and acceptance of the system. Visible intercultural variables concern presentation (colors, time and date format, icons, font size, window size, form, layout, widget position like the position of navigation bar) and language (font, direction of writing, naming) level of a product (appearing above "water surface" in the iceberg metaphor). They can be recognized very easily because they are directly accessible and less determined by cultural context. Non-visible or "hidden" intercultural variables (below the "water surface") affect dialog design (menu structure and complexity, changing of dialog form, layout, widget positions, information presentation speed, frequency of changing dialogs, screen transitions) and interaction design (navigation concept, system structure, interaction path, interaction speed, usage of navigation bar, etc.) which have strong correlations to the cultural context. These variables concern the interaction and dialog level of a product and need high research priority (e.g. using special tools as suggested by [58]). Cultural variables can be used to develop an approach for the design of intercultural human-machine systems using the "method of culture-oriented design" (MCD) according to [22]: 108 as presented in Figure 2.

The MCD integrates factors from established concepts of culture-oriented design into existing concepts of HMI design. Thereby, knowledge about cultural differences is integrated into existing methods. To include intercultural aspects in human-machine interaction, a simplified version of this method will be applied in this work 


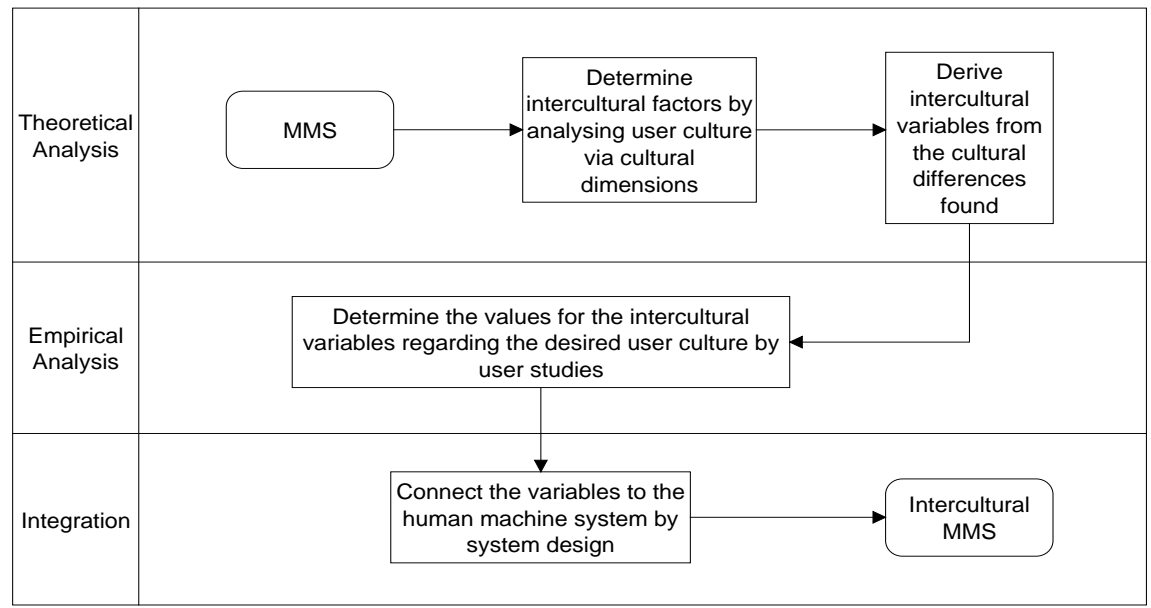

Figure 2. Simplified version of the Method of Culture-oriented Design (MCD) (Source: [17]: 66).

\subsection{User Interface Characteristics}

To make cultural dimensions available for user interface design, [18] developed characteristic factors for user interfaces and gives examples that can have an effect on user interface design. The user interface characteristics "metaphor", "mental model", "navigation", "interaction" and "presentation" are connected to the five cultural dimensions of Hofstede. However, Marcus used a purely deductive approach to obtain these connections. Many possible recommendations for web design have been derived by [59] mainly from Hofstede's knowledge without empirical foundation of all connections. Therefore, this formulated model still needs empirical validation (even if, meanwhile, there is some empirical work from Marcus himself, cf. [26]). For instance, according to [18] and [60], Chinese people (and hence users) are rather relationship and family oriented based on traditional powerful social hierarchical structures. In contrast, German users are described as event oriented regarding acts, tools, work, jobs and competition. Some tendencies regarding cultural differences can be used for the intercultural user interface design and further reflections and research. Table 2 shows a summary of general recommendations for intercultural user interface design based on [22].

\subsection{HCI Dimensions}

Based on the work of [9] [61] [62] and own studies [17] [58] [63] [64] [65] [66], the author introduced the concept of HCI dimensions to support the determination of the relationship between culture and HCI [17]. HCI dimensions (HCIDs) describe the "style of information processing" and the "interactional characteristics" of the user with the system. HCIDs are derived from the basic physical dimensions of space and time as well as from their sub-dimensions frequency, speed, duration, density and order) (cf. Table 3).

HCIDs represent the characteristics of HCI by describing the HCI style of the user, i.e. the path of information processing and the interaction style exhibited 
Table 2. Summary of recommendations for intercultural HCI design according to the user interface characteristics regarding China and Germany (summarized by the author in accordance to table 6-3 in [22]: 138 as well as to [22]: 305-317).

\begin{tabular}{|c|c|c|}
\hline $\begin{array}{l}\text { User Interface } \\
\text { Characteristics }\end{array}$ & China & Germany \\
\hline Metaphor & $\begin{array}{l}\text { Use clear hierarchy and } \\
\text { representation instead of abstraction }\end{array}$ & $\begin{array}{l}\text { Use representation } \\
\text { instead of abstraction }\end{array}$ \\
\hline Mental model & $\begin{array}{l}\text { Use many references without sequence of } \\
\text { relevance, simple mental models, clear } \\
\text { articulation, limited choice and binary logic }\end{array}$ & $\begin{array}{l}\text { Use few references } \\
\text { with sequence of } \\
\text { relevance and fuzzy logic }\end{array}$ \\
\hline Navigation & $\begin{array}{l}\text { Use limited and predefined } \\
\text { choice and navigation }\end{array}$ & $\begin{array}{l}\text { Use open access and arbitrary } \\
\text { choice and unique navigation }\end{array}$ \\
\hline Interaction & $\begin{array}{l}\text { Use personalized but team-oriented } \\
\text { systems giving direct error messages, } \\
\text { guided help and providing } \\
\text { face-to-face interaction }\end{array}$ & $\begin{array}{l}\text { Use distant but supportive } \\
\text { (error) messages providing open } \\
\text { and flexible interaction with the } \\
\text { system (e.g., full text search) }\end{array}$ \\
\hline Presentation & $\begin{array}{l}\text { Use formal speech providing high } \\
\text { contextual relationship-oriented } \\
\text { information as well as feminine colors }\end{array}$ & $\begin{array}{l}\text { Use informal speech providing } \\
\text { low contextual task-oriented } \\
\text { information as well as } \\
\text { masculine colors }\end{array}$ \\
\hline
\end{tabular}

Table 3. HCI Dimensions.

\begin{tabular}{ccc}
\hline $\begin{array}{c}\text { Derived physical sub-dimensions } \\
\text { [basic physical dimension] }\end{array}$ & $\begin{array}{c}\text { Information related } \\
\text { HCI dimension }\end{array}$ & $\begin{array}{c}\text { Interaction related } \\
\text { HCI dimension }\end{array}$ \\
\hline Frequency [Time] & Information frequency & Interaction frequency \\
Speed [Time] & Information speed & Interaction speed \\
Sequentiality/Priority/Order & Information & Interaction \\
[Time and Space] & order/Information parallelism & order/Interaction parallelism \\
$\begin{array}{c}\text { Density/Quantity [Time and } \\
\text { Space]/Context [Time and Space] }\end{array}$ & Information density & \\
\hline
\end{tabular}

by the user based on the concepts of "information" and "interaction" according to HCI dialogs that are characterized by transmitting pieces of information during user system interaction (cf. [67]).

Frequency, density, order and structure are concerned particularly during information processing; frequency and speed are concerned during interaction behavior. HCI dimensions can be regarded as the main factors relevant for HCI design, because they denote the basic classes for variables useful in HCI design. The view of space, time and mental aspects is strongly culture dependent (cf. [8]). HCI is, therefore, also culture dependent, because HCI dialogs, interaction, information presentation and with that HCI generally are strongly linked with time (interaction, communication) and space (layout, structure) as well as with mental aspects (relations, thoughts) (cf. [3] [68] [69]). At least one potential indicator as a measurement variable is necessary to constitute the specifics of an HCI dimension. Table 4 shows examples of indicators for some HCI dimensions. 
Table 4. HCI Dimensions represented by Specifics and Indicators.

\begin{tabular}{ccc}
\hline HCI dimension & Specifics & Indicator(s) \\
\hline Interaction frequency & $\begin{array}{c}\text { Number of interactions } \\
\text { per time unit }\end{array}$ & $\begin{array}{c}\text { Mouse clicks and mouse moves } \\
\text { per second or per session }\end{array}$ \\
Information density & $\begin{array}{c}\text { Number of information } \\
\text { units per space unit }\end{array}$ & $\begin{array}{c}\text { Numbe of words per message } \\
\text { or on the display }\end{array}$ \\
Information/Interaction & Sequence of appearance \\
parallelism/order & of information units & $\begin{array}{c}\text { Number and sequence of dialog steps } \\
\text { (e.g. number of message boxes } \\
\text { used to indicate one system error) }\end{array}$ \\
\hline
\end{tabular}

For example, the indicator "number of information units per space unit" belongs to the HCI dimension "information density" and can be expressed by the number of words displayed on the screen. The HCI dimension "interaction frequency" contains the variable "number of interactions per time unit" represented by the number of mouse clicks per second.

\subsection{Usability Engineering}

The usability of a system strongly depends on how the user can cope with the system. This knowledge can be obtained "simply" by ob-serving and asking the user during his interactions with the system. In this case the user articulates his desires and hence his needs regarding the usability of the system. This is trivial and easy, but unfortunately, this method is applied far too little in industrial HCI design even today. This is critical because, if that knowledge is missing in the final product, it will not be wanted by the user: the customer (user) cannot use it because important features are missing or it takes too long to do a certain task using this system because of wrong design.

The preconditions for intercultural usability engineering are knowledge about the cultural differences in $\mathrm{HCI}$ and its considerations in product design and product realization (cf. [3] [63] [69]). In addition to the common misunderstandings between developers and users, which lead to different product design, there are also misunderstandings because of cultural conditions. There is not only a different comprehension of the requirements of the product but also culturally dependent perspectives and views of them (cf. [70]). Hence, the developer needs much intercultural knowledge to understand a user from another culture. Furthermore, he needs competency regarding intercultural communication to enable the exchange of information with the user and to know exactly which product the user is likely to have (cf. [71] [72]). With this in mind, [21] presented an empirical study for the development of a framework for the elicitation of cultural influence in product usage to take into account culture and context in HCI design. [73] investigated the impact of culture and gender on web sites. [74] studied the influence of culture in global software engineering by thinking in terms of cultural models. [75] did an empirical study concerning the organizational, cultural and technological use in a developing country.

"Intercultural" usability engineering is a method for designing products of 
good usability for users from different cultures [3]. The term "intercultural usability engineering" is commonly used by German usability engineers [16]. "Intercultural" in this context refers to the special methods that are necessary to do usability engineering for different cultures [57]. Bad or lacking intercultural usability engineering within the development process of the product increases the development and maintenance costs through requests for change. Detailed analysis of product requirements can save up to $80 \%$ of maintenance and implementation costs of such requests for change [76]. Therefore, intercultural HCI design must already begin with the analysis of requirements before starting the design in order to avoid a reduction of the fit between user and product if products of one culture are used in another (cf. [77] [78] [79]). At the collection of culture specific user requirements and culture specific assessment of the concepts used, it must be determined how far approved methods of usability engineering are suitable. The existing cultural models should be taken into account in the process of product design in the context of intercultural usability engineering. First, the product developers must be sensitized to the difficulties of cultural influences on product development and product use. Then cultural factors influencing $\mathrm{HCI}$ must be provided to the developers and integrated into the product. Finally, the procedures, which serve to capture the knowledge acquired in concrete product design, must be institutionalized.

After the pioneer research of [79], several researchers have invested a great deal of effort to determine the best methods and settings to test the usability and user experience in cultural contexts. There is research to study cross cultural think-aloud usability testing to make some suggestions for an experimental paradigm [42]. Moreover, usability constructs are investigated by doing a crosscultural study of how users and developers experience their use of information systems [80]. The differences in usability testing in three countries as well as the interaction design and usability from an Indian perspective was described by [81]. In addition, the influence of cultural background on non-verbal communication in a usability testing situation was investigated [82] and [83] interpreted cross-cultural usability evaluation based on a case study of a hypermedia system for rare species management in Namibia. The situating media in the transfer of rural knowledge in Africa to enfranchise indigenous rural people is research by [84]. Most of these results of the mentioned research were discussed at a workshop in the frame of the conference "Interact 2011" [46]. The results of the workshop on the international comprehension of usability the application of usability methods were published by [85]. Finally, there is the trend to work on methods to take cross-cultural differences into account in design in general [86].

\subsection{Research Directions, Related Work and Empirical Studies}

The number of studies supporting the importance of taking cultural aspects into account in user interface design has been growing steadily since about 2000 (e.g., [87] [88]). However, there is relatively little literature and there are few guidelines for intercultural dialog and design for interaction (cf. [88] [27]) and very 
few especially for driver navigation systems (e.g., [90]). Most studies concern the presentation of information on web pages (e.g., [91]-[98]). Even though there are already the first pragmatic guidelines for intercultural web design [59] or intercultural HCI design [1], there are none for intercultural user interface design in specific domains such as driver navigation systems that could be used easily and effectively by HCI designers in this area. This is also supported by the overview of [99] as well as [100] presenting many activities and models for intercultural website design. There are little insights regarding interactive design, as the overview of [45] regarding intercultural information design shows- even if, for a short time, there have also been studies examining stand-alone systems and applications other than web applications (e.g., [27] [89] [101] [102]).

The cultural influences on the values of visible cultural variables of $\mathrm{HCI}$ is proven empirically in the literature on internationalization and partly implemented in products (cf. [28] [103]) regarding surface level (presentation of information, speech and general design of machine) and functional level (machine functions, service and technical documentation) of localization. Most of these studies concentrate on "visible" cultural variables such as colors (NASA standard for colors (cf. [104] [105]), icons (use of pictorial or abstract icons, cf. [22]: 135), date and time, phone numbers and address formats, spelling, typography, reading and writing directions, sorting methods (cf. [106]: 23-24), extension of texts, text processing, number of characters (cf. [107]: 77) and multimedia [108]. Also the cultural prescription and user perception of information architecture for a culture centered website was contrasted by [109] by doing a case study on Muslim online users. It was asked by [110] why social media can cross seas but not nationalisms while doing a cross-cultural comparative study of user interface in social media. The proverb "talk is silver, silence is golden" in some cultural context was confirmed by [111] via a cross cultural study on the usage of pauses in speech. A cross-cultural evaluation of the facial expressions of avatars designed by Western designers was performed by [112]. In contrast, [113] concentrated on cross-cultural differences and information systems developer values. In addition, [114] investigated culture and its effects on human interaction design with emphasis on cross-cultural perspectives between Korea and Japan. Hence, in the area of intercultural HCI design there is much research regarding the design of cross-cultural web pages and research of international product design (cf. international workshops of internationalization of products and systems (IWIPS)) as well as many guidelines regarding the visible areas of graphic user interfaces for the internationalization and localization of software.

In contrast, some cultural variables have not been thoroughly investigated so far. Study of the literature does not reveal much about research on hidden intercultural variables at the interactional level. Cultural influence on $\mathrm{HCI}$ at the interactional level, for example with respect to navigation, system structure and mental models or varying functionality has not yet been investigated in detail to develop optimal products for the specific culture. In addition, there is still little literature about the connection between visible cultural aspects and hidden in- 
tercultural variables for HCI design. The investigation of cultural differences in the information seeking process by [115] also supported the path to guidelines that available on building IT architecture [116]. Regarding different kinds of thinking, [117] proposed that the thought patterns of East Asians and Westerners differ greatly (holistic vs. analytic). Holistically minded people have a tendency to perceive a scene globally; they are more field-dependent. Analytically minded people are more field-independent because they have a tendency to perceive an object separately from the scene and tend to assign objects to categories. The relationship between cognitive styles and webpage perception is analyzed by [118]. Thereby, they studied and presented the culturally different behavior of eye movement. The different viewing patterns of Chinese, Korean and American people suggest that webpage designers should be aware of the cognitive differences existing among holistically minded people and analytically minded people, and that web pages should be designed to match the users' cognitive styles in order to enhance usability. Holistically minded people (e.g., Chinese people) scan the entire page non-linearly. Hence, the design of content should show the whole context of the website and the harmony between the foreground and background as well as the relationship among all the content areas. In contrast, the webpage design should be as clear and simple as possible for analytically minded people (e.g., German people). They tend to employ a sequential reading pattern among areas and to read from the center to the periphery of the page. Hence, the arrangement of all content areas must be considered carefully. Category titles and navigation items should be named as clearly as possible since analytically minded people tend to pay more attention to these items and gain an overall picture of the website from them. [118] also intended to define the relationship between cognitive styles and webpage layout design. This indicates once more that most intercultural studies concentrate on examining web pages. Besides, [49] also investigated cultural dimensions for user experience doing a cross-country and cross-product analysis of users' cultural characteristics. A cross-cultural study on how users and developers experience their use of information systems revealed differences in mobile Internet usage between users from Japan (e.g., high email traffic) and Korea (e.g., many downloads) depending on different value structures in Japan and Korea imprinted by culture [119]. Cultural differences in the understanding of metaphors applied in user interfaces were examined by [120]. Since the real world changes from culture to culture, the metaphors referring to the real world that are used in HCI must also be considered for the localization of user interfaces. Examination has shown that test subjects from different cultures understand metaphors differently and their expectations, which they combine with the metaphors, are also different. Moreover, an explorative study with French and Turkish users on an e-learning site by [121] improved the cross-cultural understanding of the dual structure of metaphorical icons. Hidden cultural variables in HCI design such as information speed, information frequency, and interaction speed and interaction frequency have been touched by [17] (cf. Section 3.3). 
However, all these variables can still be regarded as an open field for research in intercultural HCI design because there is just so little empirical evidence for the results in this area. In this respect, much effort must still be invested to investigate and consider hidden cultural variables in intercultural $\mathrm{HCI}$ design.

\subsection{Models and Theories}

The cultural model (iceberg metaphor) as developed by [11] is relevant for international user interface design. The relationship of user interface characteristics to Hofstede's cultural dimensions was elaborated by [122]. In contrast to [123], who generated a relationship model in cultural usability testing, [124] postulated a three-perspective model of culture, information systems and their development and use. Other authors based their approach on cultural models to study the relationship between culture and HCI. The influences of culture in global software engineering were analyzed by [74] via thinking in terms of cultural models. Based on the results of [17], the author formulated reflections on a preliminary model of culturally influenced human computer interaction to cover cultural contexts in HCI design which encompass the relationships between cultural and HCI dimensions. According to the results of an empirical study done by the author (cf. [44]), some of the correlations between the cultural dimensions and the $\mathrm{HCI}$ dimensions as well as their values were determined (cf. [17]) leading to the concept of HCI style scores, which can be computed for the designated cultural group from the Hofstede's indices. The HCI style score expresses the average degree of information density and frequency as well as interaction frequency and speed the members in the designated cultural group expect according to the model developed by the author. For instance, the lower the normalized HCI style score (ranging from 0 to 100) the lower the expected amount of information and the lower the interaction frequency. The resulting HCI style scores permit the establishment of clusters of countries that have similar HCI scores. According to these cultural clusters identified in the HCI style score continuum it can be expected that these country clusters exhibit a similar HCI style because of their similar cultural characterization defined by power distance index (PDI), individualism index (IDV), masculinity (MAS), uncertainty avoidance index (UAI) and long term orientation (LTO) (cf. Table 5).

These taxonomic results partially resemble the findings of [125] on "Saxonic", "Teutonic", "Gallic" and "Nipponic" styles. However, to generalize the postulated correlations many more studies with other cultural groups are required. To achieve this both the values of the cultural dimensions (using VSM) and the values of the HCI dimensions (such as pieces of presented information per minute, cf. [17]) must be determined for every desired culture. This can be done for indigenous groups as well by exploiting the same use cases and test settings in the arbitrary cultural groups of interest. A test tool developed by the author can be used to support this [58]. However, until there are no other values for the cultural dimensions than Hofstede's at the national level, those must be used to test the model. In addition, to further confirm findings, factor analysis can be 
Table 5. HCI Styles around the world.

\begin{tabular}{|c|c|c|}
\hline HCI style & Cultural characterization & $\begin{array}{l}\text { Normalized HCI style } \\
\text { score (group averaged) }\end{array}$ \\
\hline Asian & $\begin{array}{c}\text { PDI high, IDV low, } \\
\text { MAS middle, UAI low, LTO high }\end{array}$ & 90 \\
\hline Indian & $\begin{array}{l}\text { PDI high, IDV middle, } \\
\text { MAS middle, UAI middle, LTO middle }\end{array}$ & 70 \\
\hline African & $\begin{array}{l}\text { PDI high, IDV low, MAS middle, } \\
\text { UAI middle, LTO low }\end{array}$ & 60 \\
\hline Scandinavian & $\begin{array}{l}\text { PDI low, IDV high, MAS low, } \\
\text { UAI middle, LTO low }\end{array}$ & 40 \\
\hline Slavic & $\begin{array}{c}\text { PDI high, IDV middle, } \\
\text { MAS middle, UAI high, LTO low }\end{array}$ & 30 \\
\hline Angle-Saxon & $\begin{array}{c}\text { PDI low, IDV high, } \\
\text { MAS middle, UAI low, LTO low }\end{array}$ & 20 \\
\hline German & $\begin{array}{c}\text { PDI low, IDV middle, } \\
\text { MAS high, UAI middle, LTO low }\end{array}$ & 10 \\
\hline
\end{tabular}

applied to statistically calculate the corresponding loadings to the HCI style by clustering Hofstede's indices according to their HCI style score. The findings should refine the currently assumed rules that describe the relationship between cultural imprint and HCI style of a group (with at least 20 members). The explanatory value of this descriptive model still must be worked out.

In addition to this model, there are several other approaches towards a theory of culturally influenced human computer interaction. An explanatory theory for using management information systems in the Chinese business culture was developed by [126]. Moreover, [127] applied activity theory as a framework for accommodating cultural factors in HCI studies. Integrating activity theory into a usage-centered design approach is the method of [128] to cover environmental contexts, whereas [129] worked towards a HCI theory of cultural cognition. This systematic usage-centered design approach was extended by [130] o also cover cultural contexts by subjoining a cultural model as a new component. A theory of socio-technical interactions was outlined to explain culture by [131] integrating theory, research and application to understand culture. Using activity theory to tackle cultural contexts is very prominent (cf. [52] [128] [132]). ADA and CMU theory was compared in order to derive a theory for cultural usability [133]. However, until now, there is no final theory that would explain all relevant factors necessary to derive design recommendations for culture-centered HCI design. This still remains a task for the future.

\subsection{Processes, Standards and Tools}

International standards for HCI and usability have been emerged and commented [134]. The user-centered HCI design process is defined in ISO 9241-210 and the emerging ISO 9241-220. ISO 9241-171 can be used to integrate cultural aspects to cover intercultural HCI design processes. In addition, the working 
team "quality standards" of the German UXPA (user experience professionals association) carved out a usability engineering process that can be extended by the necessary roles, tasks, methods, documents and work products, which are necessary to take cultural aspects into account and to fit them into any cultural contexts. A company culture audit was serves to improve development team's collaboration, communication and cooperation [135]. The intercultural interaction analysis tool (IIA tool) was developed to determine the cultural differences in HCI at interaction level [58].

\section{Discussion}

\subsection{Problems and Controversies in Converging Divergences in Intercultural User Interface Design}

\subsubsection{Methodological Challenges}

The methodological problem in researching culture is that the transmission of simple systems is easier than the integration of complex systems, which can only be achieved by human creativity [136]. This applies primarily to cultural questions, which encompass and integrate the complete context of a member of a culture. This problem also confronts intercultural user interface design, which makes it compellingly necessary to deal with the combination or linkage of culture with HCI design. Therefore, along with the common issues and challenges in HCI and in HCI design (cf. [137] [138]) and in the usability engineering process (cf. [139]), problems also arise because they must work in a cultural context (cf. [5] [21] [140] or [141]). Hence, the problems in adapting HCI to the cultural background of the user must be investigated [142]. Many aspects have to be taken into account simultaneously to obtain possible cultural explanations for their effect on HCI. Alternatively, the effects of culture on HCI cannot be explained by only one single aspect but by many different influences due to the complexity of culture. Another problem in cultural research is that one cannot predict how the single parts of the cultural puzzle will fit together (cf. [136]: 130). This has implications for the use of these methods in intercultural HCI design and intercultural usability engineering (cf. [143]).

\subsubsection{Different Approaches}

Furthermore, different approaches exist for determining intercultural variables and their values. For instance, cultural dimensions arise from cultural studies that can give insight into the diversity of cultures. From cultural dimensions, intercultural factors for $\mathrm{HCI}$ design can be derived. The results thus acquired are supported argumentatively and deductively, but not yet confirmed empirically (cf. [59]: 5 et seq.). Furthermore, the connection between cultural dimensions and HCI design has not yet been studied in depth [144]. Either detailed empirical studies must follow or the results can only serve as exemplifications, but not as a scientific foundation for further research. The complement to this deductive approach is the inductive approach: Cultural markers have been determined by empirical studies (e.g., [37] [40] [145]), which are specific for a certain culture and which are preferably used within this certain culture. There is direct influ- 
ence of cultural markers on the performance of users interacting with the system and hence the connection between culture and usability (confirmed by studies from [37] [40] [41]). However, these results cannot be generalized to be valid for a complete country because the sample sizes are too small and the limited representativeness of the test persons precludes statistical results of high quality. This is one reason why there are few evident qualitative empirical studies and even fewer purely quantitative studies (cf. [146] as well as [147]) which treat the interaction of culturally different imprinted users with the system.

\subsubsection{High Research Effort}

Hidden variables are difficult to identify because they are only recognizable over time. Therefore, the reason for the lack of results regarding direct hidden intercultural variables at the interaction level is also grounded in the difficulty of accessing and measuring them. To work against these methodological difficulties in studying hidden variables, it is reasonable, to a certain degree, to regard interaction and dialog design separately. First, the cultural differences in the interaction between user and system must be investigated, and then, how the interaction affects information flow between user and system must be treated. Finally, how dialog windows should be designed for culturally different users also needs investigation, which should lead to preliminary design recommendations.

\subsubsection{Lacking Empirical Confirmation}

Not all recommendations have yet been proved empirically ac-cording to the five areas of user interface characteristics, even if there is some research in this area. Röse validated some of the aspects pointed out by Marcus doing qualitative studies in China regarding different layouts for Chinese and German users (cf. [148]). Moreover, regarding metaphors it is the case that in China hierarchical taxonomies and classifying instruments are applied rather than the case in Germany because of the high power distance values. Most of the recommendations presented must be tested and confirmed empirically in detail by additional studies before being suggested as best practices or even useful guidelines, if not already done so. Furthermore, parallel to the research literature, empirical investigations regarding intercultural user interface characteristics are necessary, more specifically by comparing several systems of different cultures (benchmark tests) as well as usability evaluations (usability testing) to determine the usability of different systems.

\subsubsection{Usage of Cultural Dimensions}

On the one hand, critics of Hofstede claim that the samples drawn from IBM's worldwide employee interview in their original study of 1967-72 are not representative. They do not provide data for actually measuring national culture differences between the countries but rather the differences within the corporate culture of IBM. Furthermore, Hofstede's approach ignores differences within a nation. The model treats a nation like a homogeneous collection of individuals who share the same structure of values. This is not correct in most cases (cf. [149]) and [150]). Some studies show inconsistencies in the values of Hofstede as 
presented by [151]: Power distance index (PDI) values for Japan, China and USA differ from those found by Hofstede. Furthermore, although much is said about what should be taken into account culturally, little empirical research is available on this topic as also pointed out, for instance, by [151]. In addition, a different behavior does not necessarily mean a different cultural (propositional) attitude, i.e. a different cognitive state in the web of belief. Restricted appreciation and mediation of cultural dimensions and models can lead to ineffective or even restricting action strategies [152]. In this case, a little cultural understanding proves to be just as bad as or even worse than no cultural understanding at all. Therefore, [152] pleads for dimension independent cultural models because they make the derivation of concrete behavior patterns possible whose explanations are founded on concrete manifestations of the culture described in contrast to models that use cultural dimensions. For instance, marrying CIIs with NLP principles as suggested by [17] means "cultural" adaptation at the individual level. The criticism concerning the correctness of Hofstede's cultural dimensions and their indices reduces confidence in them, which then implies that it is probably better or at least advisable not to build an adaptive system based on these but on parameters that represent the immediate behavior of the user with the system.

On the other hand, supporters of Hofstede's theory reject these moves away from Hofstede because numerous independent repetition studies in subsequent years confirmed Hofstede's results. Moreover, Hofstede's results referred to different subgroups of the respective populations and nevertheless showed similar national differences, which agree with Hofstede's dimension values. Furthermore, Hofstede points particularly to the different levels of culture whilst distancing himself from the list of questions (VSM) which was included with his explanations and designed for further use by the readers. According to [153] this is also because one of the consequences of his research and its results (and a starting point for criticism) is the "not reflected" appropriation and assignment of his cultural model which is seen as a useful tool for research (cf. [154]) and a useful starting point to research user interfaces in the cultural context (especially if a well founded theory is the designated goal of the research).

\subsection{Research Directions in Converging the Divergence in Intercultural User Interface Design}

The trend in research on culture and HCI is to verify preliminary models and theories by doing extensive empirical studies in various cultural contexts. Furthermore, the relationship between culture and HCI design must subsequently be elaborated upon in detail. The focus of investigating cultural differences will shift from the national level to a regional level and even to any other situation to cover all cultural contexts. Thereby, methods, models and theories will be adapted and improved upon in the near future by taking the results from many empirical studies into account to derive and optimize processes for intercultural HCI design and intercultural usability engineering and thereby establish inter- 
national norms and develop tools that finally augment the international standards of research covering arbitrary cultural contexts in HCI.

\subsubsection{Reframing HCI through Indigenous Perspectives}

"Reframing" means taking cultural aspects into account at the local level (cultural context/indigeniously) in addition to the national level. For the last years the research and literature accounting for cultural contexts in Human Computer Interaction (HCI) design have grown quickly (cf. [20] [155]). In addition, until recently, culture in HCI was considered a matter of internationalization or localization [156]. As computer use spreads around the world, these traditional approaches to culture and $\mathrm{HCI}$ have proven to be seriously insufficient approaches. According to [21] and [69], successful intercultural HCI design goes far beyond a regular design process by taking into account different mentalities, thought patterns and problem solving strategies that are anchored in culture. Usage patterns differ from culture to culture according to different power structures [9], for example flat vs. hierarchical ones or problem solving strategies being linear vs. non-linear [148]. Hence, the designer must know exactly what the user needs or wants (e.g. why and in which context [71]). In addition, local designers must adapt general HCI methods to their needs (cf., [84] [85] [157]). Feasible recommendations and guidelines for the conception, design and evaluation of issues when implementing standard HCI perspectives in local contexts, as exemplified by German developers generating products for Chinese people, can be found in [70]. Related work on culture and HCI has been compiled along with [35] [85] [158] and by the author [17]. Within culturally different groups one must also consider dependence on context, situation and experience (cf. [84]). This knowledge can be determined most precisely by using inquiry approaches or methods based on communication like interviews, focus groups or questionnaires [159]. For successful (intercultural) user interface design and (intercultural) usability engineering it is necessary that the developer understands the user [160], because they have different points of view [161]. Only by taking the perspective of a user by the HCI designer into account in order to grasp their needs depending on their world view, general knowledge, context and purpose of usage can good user interfaces of high usability be achieved. Excellent user experience design should be the result (cf. [135] [162] [163] [164]). However, problems in intercultural communication ensuring empathic access to the user requirements inhibit good usability for system design and the related user experience (cf. [5] [8]). This is because people and groups are shaped by many cultural systems, including religion, language and training as well as gender and life experience (cf. [17] [18]) representing a certain "culture", i.e. being a member of a group representing the same cultural characteristics.

\subsubsection{Recommendations and Solutions for Converging Divergence in Intercultural User Interface Design}

Several researchers working in this area of taking cultural contexts into account in HCI design have already profited from the results of empirical studies to build 
well elaborated and comprehensible work products that end in complex but valuable models, theories and tools for further and broader fruitful future research. For instance, the horizontal orientation of menus in layouts for the Chinese population was determined by [165]. A cross-cultural comparative study of users' perceptions of a webpage with the focus on the cognitive styles of Chinese, Koreans and Americans was done by [118]. Finally, [166] developed a culture-sensitive image tagging interface. Another example presents [40] who conducted an exploratory study of cultural markers based on [167] to build a culturally competent corporate multilingual web site. A pilot study in china was performed by [168] to clarify language issues in cross cultural usability testing. Finally, the path to cross-cultural technology design by creating culture-sensitive technology for local users has been augmented by [169].

In any case, it is important to take cultural context into account in designing HCI. A cross-cultural study on knowledge sharing emerged that saving face and sharing personal information is appropriate depending on the situation [170]. A total of 197 Chinese undergraduate students and 111 American undergraduate students participated in the study. The first finding was that both Chinese and American students were more willing to share personal knowledge with ingroup members than with out-group members. Furthermore, the results sho wed that common work experience between group members was more important than common national cultural background in determining a people's attitude towards knowledge sharing. Another interesting finding was that Chinese participants were more willing to share personal information with an American stranger (out-group) than a Chinese stranger (in-group), while American participants showed no such difference. In summary, these findings indicate that a global organization should take both national culture and in-group/out-group factors into consideration to facilitate knowledge sharing.

In addition, personalization and adaptation to the different user needs is necessary: “[...] Internet strategies should be localized or adjusted to unique cultures, since people want different values even from the same services across different cultures. [...] Mobile Internet services need to be personalized to individual users because value structures and usage patterns are influenced by various factors across countries. To develop personalized services, mobile Internet service providers need to segment user groups by cultural, demographical, or socioeconomic factors and monitor them, which may enable them to chase users' fast changing needs or values efficiently" ([119]: 237).

\section{Conclusion}

In the area of intercultural user interface design, the difficult investigation of methodological intercultural factors still stands at the beginning where it is acquiring results for phenomena like different habits of interacting with the system, different expectations regarding navigation within hyperspace or different mental models. It is still decisive in the area of intercultural user interface design to bridge the gap between cultural aspects and those specifically for user inter- 
face design. This is especially the case with respect to the current lack of research regarding culturally imprinted interaction and dialog design based on empirical studies regarding hidden cultural variables. Even if the research concerning culture-centered HCI design is growing enormously, it is the most important to integrate the results from empirical studies considering cultural contexts in HCI design and thereby, provides the basis of both data to feed models and construct theories and the basis of the graduated measuring rod for their verification representing the path to get the convergent divergence in the field of intercultural user interface design. Even if there is still a long way to go, there are already converging strategies that have to be exploited and developed further to reduce the divergence in intercultural user interface design. One possible approach to this is to reframe HCI by taking cultural aspects into account at the local level (cultural context/indigenously) in addition to the national level up to the approach of designing in the wild. These procedures can be supported by using a mix of IUID methods applying user interface characteristics, human computer interaction dimensions. It is a matter of future research to determine which combination of converged approaches, methods, processes and tools will survive and lead the research paradigm in order to reduce divergence in IUID.

\section{References}

[1] Röse, K. and Zühlke, D. (2001) Culture-Oriented Design: Developers' Knowledge Gaps in this Area. In: Johannsen, G., Ed., 8th IFAC/IFIPS/IFORS/IEA Symposium on Analysis, Design, and Evaluation of Human-Machine Systems, Kassel, September 18-20 2001, 11-16.

[2] Marcus, A. (2007) Global/Intercultural User-Interface Design. In: Jacko, J. and Spears, A., Eds., The Human-Computer Interaction Handbook, Lawrence Erlbaum Associates, Mahwah.

[3] Honold, P. (2000) Intercultural Usability Engineering: Barriers and Challenges from a German Point of View. In: Day, D., Galdo, E.D. and Prabhu, G.V., Eds., Designing for Global Markets. 2nd International Workshop on Internationalisation of Products and Systems, 137-147.

[4] Heimgärtner, R. (2014) Intercultural User Interface Design. In: Blashki, K. and Isaias, P., Eds., Emerging Research and Trends in Interactivity and the HumanComputer Interface, Information Science Reference (an Imprint of IGI Global), Hershey, 1-33. https://doi.org/10.4018/978-1-4666-4623-0.ch001

[5] Heimgärtner, R., Tiede, L.-W. and Windl, H. (2011) Empathy as Key Factor for Successful Intercultural HCI Design. In: Marcus, A., Ed., Proceedings of 14 th International Conference on Human-Computer Interaction, Springer Berlin/Heidelberg, 557-566. https://doi.org/10.1007/978-3-642-21708-1_62

[6] Chamberlain, A., Crabtree, A., Rodden, T., Jones, M. and Rogers, Y. (2012) Research in the Wild: Understanding in the Wild Approaches to Design and Development. Proceedings of the Designing Interactive Systems Conference, Newcastle Upon Tyne, 11-15 June 2012, 795-796.

https://doi.org/10.1145/2317956.2318078

[7] Schwartz, S.H. (1992) Universals in the Content and Structure of Values: Theoretical Advances and Empirical Tests in 20 Countries. Advances in Experimental Social Psychology, 25, 1-65.

[8] Hall, E.T. (1959) The Silent Language. Doubleday, New York. 
[9] Hofstede, G.H., Hofstede, G.J. and Minkov, M. (2010) Cultures and Organizations: Software of the Mind. McGraw-Hill, Maidenhead.

[10] Hofstede, G. (1984) Culture's Consequences: International Differences in WorkRelated Values. Sage, Beverly Hills, Calif.

[11] Hoft, N.L. (1996) Developing a Cultural Model. In: Del Galdo, E.M. and Nielsen, J., Eds., International Users Interface, John Wiley \& Sons, Inc., 41-73.

[12] Thomas, A. (1996) Psychologie interkulturellen Handelns. Hogrefe, Göttingen; Seattle.

[13] Hodicová, R. (2007) Psychische Distanz und Internationalisierung von KMU: Empirische Untersuchung am Beispiel des Sächsisch-tschechischen Grenzraumes. Duv.

[14] Hofstede, G. (1994) VSM94: Values Survey Module 1994 Manual. IRIC, Tilberg, Netherlands.

[15] Röse, K., Liu, L. and Zühlke, D. (2001) Design Issues in Mainland China: Demands for a Localized Human-Machine-Interaction Design. In: Johannsen, G., Ed., 8 th IFAC/IFIPS/IFORS/IEA Symposium on Analysis, Design, and Evaluation of Human-Machine Systems, Preprints, Kassel, 17-22.

[16] Zühlke, D. (2004) Useware-Systeme für internationale Märkte. In: UsewareEngineering für technische Systeme, Springer, Berlin, Heidelberg, 142-164.

[17] Heimgärtner, R. (2012) Cultural Differences in Human-Computer Interaction. Oldenbourg Verlag.

[18] Marcus, A. (2001) Cross-Cultural User-Interface Design. In: Smith, M.J.S.G., Ed., Proceedings of the Conference on Human-Computer Interface Internat (HCII), Lawrence Erlbaum Associates, Mahwah, NJ, USA, 502-505.

[19] Rau, P.-L.P., Plocher, T. and Choong, Y.-Y. (2012) Cross-Cultural Design for IT Products and Services. Taylor \& Francis, Boca Raton, FL.

[20] Shen, S.-T., Woolley, M. and Prior, S. (2006) Towards Culture-Centred Design. Interacting with Computers, 18, 820-852.

[21] Honold, P. (2000) Culture and Context: An Empirical Study for the Development of a Framework for the Elicitation of Cultural Influence in Product Usage. International Journal of Human-Computer Interaction, 12, 327-345. https://doi.org/10.1080/10447318.2000.9669062

[22] Röse, K. (2002) Methodik zur Gestaltung interkultureller Mensch-MaschineSysteme in der Produktionstechnik. Univ., Kaiserslautern.

[23] Vdma (2009) Software-Internationalisierung Leitfaden. VDMA Fachverband Software, Frankfurt a.M.

[24] DR. International (2003) Developing International Software.

[25] Schmitz, K.-D. and Wahle, K. (2000) Softwarelokalisierung. Stauffenburg-Verl., Tübingen.

[26] Marcus, A. (2006) Cross-Cultural User-Experience Design. In: Barker-Plummer, D., Cox, R. and Swoboda, N., Eds., Diagrammatic Representation and Inference, Springer Berlin Heidelberg, 16-24. https://doi.org/10.1007/11783183_4

[27] Kralisch, A. (2006) The Impact of Culture and Language on the Use of the Internet Empirical Analyses of Behaviour and Attitudes Berlin.

[28] Nielsen, J. (1990) Designing User Interfaces for International Use. Elsevier, Amsterdam.

[29] Del Galdo, E.M. and Nielsen, J. (1996) International User Interfaces. Wiley, New York. 
[30] Day, D.L. (1991) The Cross-Cultural Study of Human-Computer Interaction: A Review of Research Methodology, Technology Transfer, and the Diffusion of Innovation.

[31] Cagiltay, K. (1999) Culture and Its Effects on Human-Computer-Interaction. In: Collis, B. and Oliver, R., Eds., Proceedings of World Conference on Educational Multimedia, Hypermedia and Telecommunications 1999, AACE, Chesapeake, VA, 1626-1626.

[32] Jetter, H.-C. (2004) Interkulturelles UI Design und UI Evaluation Universität Konstanz.

[33] Leidner, D.E. and Kayworth, T. (2006) Review: A Review of Culture in Information Systems Research: Toward a Theory of Information Technology Culture Conflict. MIS Quarterly, 30, 357-399.

[34] Vatrapu, R. and Suthers, D. (2007) Culture and Computers: A Review of the Concept of Culture and Implications for Intercultural Collaborative Online learning. Lecture Notes in Computer Science: IWIC 07 Proceedings of the 1 st International Conference on Intercultural Collaboration, Springer-Verlag Berlin, Heidelberg, 260-275. https://doi.org/10.1007/978-3-540-74000-1_20

[35] Clemmensen, T. and Roese, K. (2010) An Overview of a Decade of Journal Publications about Culture and Human-Computer Interaction (HCI). Human Work Interaction Design: Usability in Social, Cultural and Organizational Contexts. IFIP Advances in Information and Communication Technology, 316, 98-112. https://doi.org/10.1007/978-3-642-11762-6_9

[36] Aykin, N. (2004) Usability and Internationalization of Information Technology Lawrence Erlbaum Associates Inc.

[37] Badre, A. and Barber, W. (1998) Culturabilty: The Merging of Culture and Usabilty. Proceedings of the 4 th Conference on Human Factors and the Web AT and T Labs, Basking Ridge, NJ, USA.

[38] Hermeking, M. (2001) Kulturen und Technik. Waxmann, München.

[39] Rößger, P. and Hofmeister, J. (2003) Cross Cultural Usability: An International Study on Driver Information Systems. Human-Computer Interaction.

[40] Sun, H. (2001) Building a Culturally Competent Corporate Web Site: An Exploratory Study of Cultural Markers in Multilingual Web Design. Proceedings of the 19th Annual International Conference on Computer Documentation, Sante Fe, 2124 October 2001, 95-102. https://doi.org/10.1145/501516.501536

[41] Vöhringer-Kuhnt, T. (2002) The Influence of Culture on Usability Freie Universität Berlin.

[42] Clemmensen, T. and Goyal, S. (2004) Studying cross cultural Think-Aloud Usability TESting-Some Suggestions for an Experimental Paradigm. In: Kjeldskov, J., Skov, M.B. and Stage, J., Eds., Proceedings of the Fourth Danish Human-Computer Interaction Research Symposium, Centertryk, Aalborg University, Denmark, 16 November 2004, 25-28.

[43] Reinecke, K., Reif, G. and Bernstein, A. (2007) Cultural User Modeling With CUMO: An Approach to Overcome the Personalization Bootstrapping Problem. First International Workshop on Cultural Heritage on the Semantic Web at the 6 th International Semantic Web Conference (ISWC 2007), Busan, South Korea.

[44] Heimgärtner, R. (2007) Cultural Differences in Human Computer Interaction: Results from Two Online Surveys. In: Osswald, A., Ed., Open Innovation, UVK, Konstanz, 145-158.

[45] Thissen, F. (2008) Interkulturelles Informationsdesign. In: Weber, W., Ed., Kom- 
pendium Informationsdesign, Berlin, Heidelberg, 387-424.

https://doi.org/10.1007/978-3-540-69818-0_15

[46] Abdelnour-Nocera, J., Kurosu, M., Clemmensen, T., Bidwell, N., Vatrapu, R., Winschiers-Theophilus, H., Evers, V., Heimgärtner, R. and Yeo, A. (2011) ReFraming HCI through Local and Indigenous Perspectives. In: Campos, P., Graham, N., Jorge, J., Nunes, N., Palanque, P. and Winckler, M., Eds., Lecture Notes in Computer Science. Springer-Verlag, Berlin; New York, 738-739.

https://doi.org/10.1007/978-3-642-23768-3_141

[47] Rau, P.-L.P., Plocher, T. and Choong, Y.-Y. (2012) International Usability Evaluation. In: Patrick Rau, P.-L., Plocher, T. and Choong, Y.-Y., Eds., CrossCultural Design for IT Products and Services, CRC Press, 191-200. https://doi.org/10.1201/b12679-17

[48] Sun, H. (2012) Cross-Cultural Technology Design: Creating Culture-Sensitive Technology for Local Users. Oxford University Press, Oxford; New York.

[49] Lee, I., Choi, G.W., Kim, J., Kim, S., Lee, K., Kim, D., Han, M., Park, S.Y. and An, Y. (2008) Cultural Dimensions for User Experience: Cross-Country and Cross-Product Analysis of Users' Cultural Characteristics. People and Computers, 1, 3-12.

[50] Sturm, C. (2002) TLCC-Towards a Framework for Systematic and Successful Product Internationalization. International Workshop on Internationalisation of Products and Systems, Austin/Texas, USA.

[51] Esselink, B. (1998) A Practical Guide to Software Localization: For Translators, Engineers and Project Managers. Benjamins, Amsterdam.

[52] Nardi, B.A. (1996) Context and Consciousness: Activity Theory and HumanComputer Interaction. MIT Press, Cambridge, Mass.

[53] Norman, D.A. and Draper, S. (1986) User Centered System Design: New Perspectives on Human-Computer Interaction Lawrence Erlbaum Associates.

[54] Kersten, G.E., Kersten, M.A. and Rakowski, W.M. (2002) Software and Culture: Beyond the Internationalization of the Interface. Journal of Global Information Management, 10, 86-101. https://doi.org/10.4018/jgim.2002100105

[55] Aykin, N. (2005) Usability and Internationalization of Information Technology. Mahwah, NJErlbaum.

[56] Law, W.K. and Perez, K. (2005) Cross-Cultural Implementation of Information System. Journal of Cases on Information Technology, 7, 121-130. https://doi.org/10.4018/jcit.2005040108

[57] Honold, P. (1999) Cross-Cultural or Intercultural-Some Findings on International Usability Testing. In: Prabhu, G.V. and Del Galdo, E.M., Eds., First International Workshop on Internationalisation of Products and Systems (IWIPS 1999), New York, Backhouse Press, Rochester, 107-122.

[58] Heimgärtner, R. (2008) A Tool for Getting Cultural Differences in HCI. In: Asai, K., Ed., Human Computer Interaction: New Developments, InTech, Rijeka, 343-368. https://doi.org/10.5772/5870

[59] Marcus, A. and Gould, E.W. (2000) Cultural Dimensions and Global Web User-Interface Design: What? So What? Now What?

[60] Röse, K., Liu, L. and Zühlke, D. (2001) Design Issues in Mainland China and Western Europe: Similarities and Differences in the Area of Human-MachineInteraction Design. In: Smith, M.J. and Salvendy, G., Eds., Systems, Social and Internationalization Design Aspects of Human-Computer Interaction, CRC Press, Boca Raton, 532-536.

[61] Schlögl, C. (2005) Information and Knowledge Management: Dimensions and 
Approaches. Information Research, 10, 10-14.

[62] Hall, E.T. and Hall, M.R. (2004) Understanding Cultural Differences: [Germans, French and Americans]. Intercultural Press, Yarmouth, Me.

[63] Heimgärtner, R. (2005) Research in Progress: Towards Cross-Cultural Adaptive Human-Machine-Interaction in Automotive Navigation Systems. In: Day, D. and Del Galdo, E.M., Eds., Proceedings of the Seventh International Workshop on Internationalisation of Products and Systems (IWIPS 2005), Amsterdam, 97-111.

[64] Heimgärtner, R. (2007) Measuring Cultural Differences in HCI as Preparatory Work for Cultural Adaptability in Navigation Systems: Results from the Second Online Survey. In: Evers, V. and Mandl, C.S.A.M.A.M.R.A.E.C.M.I.A.T., Eds., Proceedings of the Eighth International Workshop on Internationalisation of Products and Systems, Merida, 28-30 June 2007, Product \& Systems Internationalisation, Inc., 43-54.

[65] Heimgärtner, R. (2013) Reflections on a Model of Culturally Influenced Human Computer Interaction to Cover Cultural Contexts in HCI Design. International Journal of Human-Computer Interaction, 29, 205-219.

[66] Heimgärtner, R. and Kindermann, H. (2012) Revealing Cultural Influences in Human Computer Interaction by Analyzing Big Data in Interactions. In: Huang, R., Ghorbani, A., Pasi, G., Yamaguchi, T., Yen, N. and Jin, B., Eds., Active Media Technology, Springer Berlin Heidelberg, 572-583.

https://doi.org/10.1007/978-3-642-35236-2_58

[67] Bernsen, N.O., Dybkjær, H. and Dybkjær, L. (1998) Designing Interactive Speech Systems. Springer, London.

[68] Preim, B. and Dachselt, R. (2010) Interaktive Systeme-Band I: Grundlagen, Graphical User Interfaces, Informationsvisualisierung. Springer Verlag, Berlin, Heidelberg.

[69] Röse, K. (2002) Model of Culture and Their Applicability for Designing User Interfaces. Proceedings of the Conference WWDU 2002-World Wide Work, Berchtesgaden.

[70] Heimgärtner, R. and Tiede, L.W. (2008) Technik und Kultur: Interkulturelle Erfahrungen bei der Produktentwicklung für China. In: Rösch, O., Ed., Interkulturelle Kommunikation, Berlin, Verlag News \& Media, 149-162.

[71] Holzinger, A. (2005) Usability Engineering for Software Developers. Communications of the ACM, 48, 71-74. https://doi.org/10.1145/1039539.1039541

[72] Honold, P. (1999) Cross-Cultural Usability Engineering: Development and State of the Art. Proceedings of HCI International Conference on Human-Computer Interaction: Ergonomics and User Interfaces, L. Erlbaum Associates Inc., 1232-1236.

[73] Simon, S.J. (2000) The Impact of Culture and Gender on Web Sites: An Empirical Study. SIGMIS Database, 32, 18-37. https://doi.org/10.1145/506740.506744

[74] Shah, H., Nersessian, N.J., Harrold, M.J. and Newstetter, W. (2012) Studying the Influence of Culture in Global Software Engineering: Thinking in Terms of Cultural Models. Proceedings of the 4th International Conference on Intercultural Collaboration, Bengaluru, 21-23 March 2012, 77-86. https://doi.org/10.1145/2160881.2160894

[75] Dasgupta, S. and Gupta, B. (2010) Organizational Culture and Technology Use in a Developing Country: An Empirical Study. Proceedings of SIG GlobDev Third Annual Workshop, Saint Louis, 12 December 2010.

[76] Mutschler, B. and Reichert, M. (2004) Usability-Metriken als Nachweis der Wirtschaftlichkeit von Verbesserungen der Mensch-Maschine-Schnittstelle. Pro- 
ceedings of the IWSM/MetriKon Workshop on Software Metrics (IWSM/MetriKon'04), Königs Wusterhausen.

[77] Plocher, T. and Honold, P. (2000) Culturally-Adapted Product in the Global Market: Dealing with the Naysayers. Proceedings of the Paper Presented at the CHI 2000, The Hague.

[78] Beu, A., Honold, P. and Yuan, X. (2000) How to Build Up an Infrastructure for Intercultural Usability Engineering: Ease and Joy of Use for Complex Systems at Siemens. International Journal of Human-Computer Interaction, 12, 347-358. https://doi.org/10.1080/10447318.2000.9669063

[79] Honold, P. (2000) Interkulturelles Usability Engineering: Eine Untersuchung zu kulturellen Einflüssen auf die Gestaltung und Nutzung technischer Produkte. VDI Verl., Düsseldorf.

[80] Clemmensen, T., Hertzum, M., Hornbæk, K., Kumar, J., Shi, Q. and Yammiyavar, P. (2007) Usability Constructs: A Cross-Cultural Study of How Users and Developers Experience Their Use of Information Systems.

[81] Clemmensen, T. (2010) A Comparison of What Is Part of Usability Testing in Three Countries. In: Katre, D., Orngreen, R., Yammiyavar, P. and Clemmensen, T., Eds., Human Work Interaction Design: Usability in Social, Cultural and Organizational Contexts, Springer Berlin Heidelberg, 31-45. https://doi.org/10.1007/978-3-642-11762-6_3

[82] Yammiyavar, P., Clemmensen, T. and Kumar, J. (2008) Influence of Cultural Background on Non-Verbal Communication in a Usability Testing Situation. International Journal of Design, 2, 2.

[83] Paterson, B., Winschiers-Theophilus, H., Dunne, T.T., Schinzel, B. and Underhill, L.G. (2011) Interpretation of a Cross-Cultural Usability Evaluation: A Case Study Based on a Hypermedia System for Rare Species Management in Namibia. Interacting with Computers, 23, 239-246. https://doi.org/10.1016/j.intcom.2011.03.002

[84] Bidwell, N., Winschiers-Theophilus, H., Koch Kapuire, G. and Rehm, M. (2011) Pushing Personhood into Place: Situating Media in the Transfer of Rural Knowledge in Africa. International Journal of Human-Computer Studies, 69, 618-631.

[85] Röbig, S., Didier, M. and Bruder, R. (2010) Internationales Verständnis von Usability sowie Methodenanwendung im Bereich der Usability. In Proceedings of the Grundlagen-Methoden-Technologien, VDI Fachtagung USEWARE 2010 (BadenBaden 2010), 345-354.

[86] Dinet, J., Vivian, R. and Brangier, E. (2011) Towards Future Methods to Take into Account Cross-Cultural Differences in Design: An Example with the "Expert Community Staff” (ECS). In: Marcus, A., Ed., Design, User Experience, and Usability. Theory, Methods, Tools and Practice, Springer Berlin Heidelberg, 53-61. https://doi.org/10.1007/978-3-642-21675-6_6

[87] Evers, V. (2003) Cross-Cultural Aspects of User Understanding and Behaviour: Evaluation of a Virtual Campus Website by User from North America, England, the Netherlands and Japan. In: Evers, V., Röse, K., Honold, P., Coronado, J. and Day, D., Eds., Proceedings of the 5 th International Workshop on Internationalisation of Products and Systems (IWIPS 2003), University of Kaiserslautern, Berlin, 17-19 July 2003, 189-210.

[88] Smith, A. and Chang, Y. (2003) Quantifying Hofstede and Developing Cultural Fingerprints for Website Acceptability. In: Evers, V.R.K.H.P.C.J.D.D., Ed., Proceedings of the 5 th International Workshop on Internationalisation of Products and Systems (IWIPS 2003), University of Kaiserslautern, Berlin, 17-19 July 2003, 89-102.

[89] Kamentz, E. (2006) Adaptivität von hypermedialen Lernsystemen: Ein 
Vorgehensmodell für die Konzeption einer Benutzermodellierungskomponente unter Berücksichtigung kulturbedingter Benutzereigenschaften Univ., Hildesheim, 293.

[90] Rössger, P. (2003) An International Comparison of the Usability of DriverInformation-Systems. In: Evers, V.R.K.H.P.C.J.D.D., Ed., Proceedings of the 5 th International Workshop on Internationalisation of Products and Systems (IWIPS 2003), University of Kaiserslautern, Berlin, 17-19 July 2003, 129-134.

[91] Hodemacher, D., Jarman, F. and Mandl, T. (2005) Kultur und Web-Design: Ein empirischer Vergleich zwischen Großbritannien und Deutschland. In: Stary, C., Ed., Mensch \& Computer 2005: Kunst und Wissenschaft-Grenzüberschreitungen der interaktiven ART, Oldenbourg Verlag, München, Wien, 93-101.

[92] Marcus, A. (2003) Global and Intercultural User Interface Design. The HumanComputer Interaction Handbook: Fundamentals, Evolving Technologies and Emerging Applications.

[93] Dormann, C. and Chisalita, C. (2002) Cultural Values in Web Site Design.

[94] Baumgartner, V.-J. (2003) A Practical Set of Cultural Dimensions for Global UserInterface Analysis and Design Fachhochschule Joanneum, Graz, Austria.

[95] Park, S.J. and Wiedenbeck, S. (2007) Global User-Interface Design: Characteristics of Multinational Corporate Websites Drexel University, College of Information Science and Technology.

[96] Stengers, H., Troyer, O., Baetens, M., Boers, F. and Mushtaha, A. (2004) Localization of Web Sites: Is There Still a Need for It? International Workshop on Web Engineering (HyperText 2004 Conference), Santa Cruz.

[97] Sun, H. (2001) Building a Culturally-Competent Corporate Website: An Exploratory Study of Cultural Markers in Multilingual Web Design. Proceedings of the 19th Annual International Conference on Computer Documentation (ACM), Sante Fe, 95-102.

[98] Callahan, E. (2005) Cultural Similarities and Differences in the Design of University Web Sites. Journal of Computer-Mediated Communication, 11, 239-273. https://doi.org/10.1111/j.1083-6101.2006.tb00312.x

[99] Sturm, C. and Mueller, C.H. (2003) Putting Theory into Practice: How to Apply Cross-Cultural Differences to User Interface Design? In: Rauterberg, M., Menozzi, M. and Wesson, J., Eds., Human-Computer Interaction: INTERACT 03; IFIP TC13 International Conference on Human-Computer Interaction, 1-5 September 2003, International Federation for Information Processing, 1051-1052.

[100] Fitzgerald, W. (2004) Models for Cross-Cultural Communications for Cross-Cultural Website Design.

[101] Lewandowitz, L., RÖSSGER, P. and Vöhringer-Kuhnt, T. (2006) Asiatische vs. europäische HMI Lösungen von Fahrerinformationssystemen. Useware 2006 VDI, Düsseldorf, 279-287.

[102] Braun, B.-M., Röse, K. and Rössger, P. (2007) Localizing for the Korean Market: Actually Being There with a Multi-Method Approach. In: Evers, V., Sturm, C., Alberto, M., Rocha, M., Cambranes Mart।Inez, E. and Mandl, T., Eds., Proceedings of the Eighth International Workshop on Internationalisation of Products and Systems, Merida, 28-30 June 2007, Product \& Systems Internationalisation, Inc., 55-62.

[103] Evers, V. and Day, D. (1997) The Role of Culture in Interface Acceptance. Proceedings of the IFIP TC13 Interantional Conference on Human-Computer Interaction, 260-267. https://doi.org/10.1007/978-0-387-35175-9_44 
[104] Currie, N.J. and Peacock, B. (2002) International Space Station Robotic Systems Operations: A Human Factors Perspective. Human Factors and Ergonomics Society.

[105] Ou, L.C., Luo, M.R., Woodcock, A. and Wright, A. (2004) A Study of Colour Emotion and Colour Preference. Part I: Colour Emotions for Single Colours. Color Research \& Application, 29, 3. https://doi.org/10.1002/col.20010

[106] Shneiderman, B., Plaisant, C., Cohen, M. and Jacobs, S. (2009) Designing the User Interface: Strategies for Effective Human-Computer Interaction. Addison-Wesley Publishing Company, Boston.

[107] Rätzmann, M. (2004) Software-Testing \& Internationalisierung. Galileo Press, Bonn.

[108] Krömker, H. (2000) Introduction. International Journal of Human-Computer Interaction, 12, 281-284. https://doi.org/10.1080/10447318.2000.9669059

[109] Emma, N.M.I., Nor, L.M.N. and Shafie, M. (2009) Trust or Distrust in the WebMediated Information Environment (W-MIE): A Perspective of Online Muslim Users. Journal of Enterprise Information Management, 22, 5.

[110] Tateishi, M. and Toma, T. (2010) A Cross-Cultural Comparative Study of User Interface in Social Media: Why Social Media Can Cross Seas But Not Nationalisms.

[111] Endrass, B., Rehm, M., André, E. and Nakano, Y. (2008) Talk Is Silver, Silence Is Golden: A Cross Cultural Study on the Usage of Pauses in Speech. Proceedings of the IUI workshop on Enculturating Conversational Interfaces.

[112] Koda, T., Rehm, M. and Andre, E. (2008) Cross-Cultural Evaluations of Avatar Facial Expressions Designed by Western Designers. Lecture Notes in Computer Science, 5208, 245-252. https://doi.org/10.1007/978-3-540-85483-8_25

[113] Kankanhalli, A., Tan, B.C.Y., Wei, K.-K. and Holmes, M.C. (2004) Cross-Cultural Differences and Information Systems Developer Values. Decision Support Systems, 38, 183-195.

[114] Lee, K.-P. (2007) Culture and Its Effects on Human Interaction with Design: With the Emphasis on Cross-Cultural Perspectives between Korea and Japan.

[115] Komlodi, A. (2005) Cross-Cultural Study of Information Seeking. Proceedings of the International Conference on Human-Computer Interaction (HCII 2005). First International Conference on Usability and Internationalization, Springer, Berlin, New York, Las Vegas, Nevada, USA.

[116] Koning, H., Dormann, C. and Van Vliet, H. (2002) Practical Guidelines for the Readability of IT-Architecture Diagrams. Proceedings of the 20 th Annual International Conference on Computer Documentation, Toronto, 20-23 October 2002, 9099. https://doi.org/10.1145/584955.584969

[117] Nisbett, R.E. (2003) The Geography of Thought: How Asians and Westerners Think Differently ... and Why. Free Press, New York.

[118] Dong, Y. and Lee, K. (2008) A Cross-Cultural Comparative Study of Users' Perceptions of a Webpage: With a Focus on the Cognitive Styles of Chinese, Koreans and Americans. International Journal of Design, 2, 2.

[119] Lee, Y., Kim, J., Lee, I. and Kim, H. (2002) A Cross-Cultural Study on the Value Structure of Mobile Internet Usage: Comparison between Korea and Japan. Journal of Electronic Commerce Research, 3, 227-239.

[120] Evers, V., Kukulska-Hulme, A. and Jones, A. (1999) Cross-Cultural Understanding of Interface Design: A Cross-Cultural Analysis of Icon Recognition. In Del Galdo, E. and Prahbu, G., Eds., Proceedings of the International Workshop on Internationalisation of Products and Systems, IWIPS 1999, Rochester, NY, 173-182. 
[121] Rizvanoğlu, K. and Öztürk, Ö. (2009) Cross-Cultural Understanding of the Dual Structure of Metaphorical Icons: An Explorative Study with French and Turkish Users on an E-Learning Site. Proceedings of the 3rd International Conference on Internationalization, Design and Global Development: Part of HCI International 2009, San Diego, Springer-Verlag, 89-98.

[122] Marcus, A. and Gould, E.W. (2000) Crosscurrents: Cultural Dimensions and Global Web User-Interface Design. Interactions, 7, 32-46. https://doi.org/10.1145/345190.345238

[123] Shi, Q. and Clemmensen, T. (2007) Relationship Model in Cultural Usability Testing. In: Aykin, N., Ed., Usability and Internationalization. HCI and Culture, Springer Berlin/Heidelberg, 422-431. https://doi.org/10.1007/978-3-540-73287-7_51

[124] Kappos, A. and Rivard, S. (2008) A Three-Perspective Model of Culture, Information Systems, and Their Development and Use. MIS Q., 32, 601-634.

[125] Galtung, J. (1981) Structure, Culture, and Intellectual Style: An Essay Comparing Saxonic, Teutonic, Gallic and Nipponic Approaches. Social Science Information, 20, 817. https://doi.org/10.1177/053901848102000601

[126] Martinsons, M.G. and Westwood, R.I. (1997) Management Information Systems in the Chinese Business Culture: An Explanatory Theory. Information \& Management, 32, 215-228.

[127] Maier, E. (2005) Activity Theory as a Framework forAccommodating Cultural Factors in HCI Studies. In: Auinger, A., Ed., Workshops-Proceedings der 5. fachübergreifenden Konferenz Mensch und Computer 2005. Internationalisierung von Informationssystemen: Kulturelle Aspekte der Mensch-Maschine-Interaktion, Wien, 69-79.

[128] Constantine, L. (2009) Human Activity Modeling: Toward a Pragmatic Integration of Activity Theory and Usage-Centered Design Human-Centered Software Engineering, In: Seffah, A., Vanderdonckt, J. and Desmarais, M., Eds., Springer London, 27-51.

[129] Faiola, A. (2006) Toward an HCI Theory of Cultural Cognition.

[130] Windl, H. and Heimgärtner, R. (2013) Intercultural Design for Use-Extending Usage-Centered Design by Cultural Aspects. HCII 2013, Springer, Las Vegas.

[131] Wyer, R.S., Chiu, C.-Y. and Hong, Y.-Y. (2009) Understanding Culture: Theory, Research, and Application. Psychology Press, New York.

[132] Kaptelinin, V. and Nardi, B. (2006) Acting with Technologie: Activity Theory and Interaction Design. MIT Press Cambridge, Cambridge, MA.

[133] Clemmensen, T. (2009) Towards a Theory of Cultural Usability: A Comparison of ADA and CMU Theory. In: Kurosu, M., Ed., Human Centered Design. HCD 2009. Lecture Notes in Computer Science, Vol. 5619, Springer, Berlin, Heidelberg. https://doi.org/10.1007/978-3-642-02806-9_48

[134] Bevan, N. (2001) International Standards for HCI and Usability. International Journal of Human-Computer Studies, 55, 533-552.

[135] Gould, E. and Marcus, A. (2011) Company Culture Audit to Improve Development Team's Collaboration, Communication, and Cooperation Design, User Experience, and Usability. In: Marcus, A. Ed., Theory, Methods, Tools and Practice, Springer Berlin/Heidelberg, 415-424.

[136] Hall, E.T. (1976) Beyond Culture. Anchor Books, New York.

[137] Chen, Q. (2001) Human Computer Interaction Issues and Challenges Idea Group Pub., Hershey, Pa. 
[138] Reiterer, H. (2008) Seminar Reader: Future Challenges and Trends in HCI Human-Computer Interaction Group. University of Konstanz, Konstanz.

[139] Holzinger, A. and Weidmann, K.-H. (2005) Empowering Software Quality: How Can Usability Engineering Reach These Goals? 1 st Usability Symposium, HCI \& UE Workgroup, Vienna, 8 November 2005, Austrian Computer Society.

[140] Clemmensen, T., Yammiyavar, P., Orngreen, R. and Katre, D. (2010) Usability in a Cultural Context: A Report on the Scope, Process and Research Results of Cult Usab-The Cultural Usability Project. In: Katre, D., Orngreen, R., Yammiyavar, P. and Clemmensen, T., Eds., Human Work Interaction Design: Usability in Social, Cultural and Organizational Contexts. IFIP Advances in Information and Communication Technology, Vol 316. Springer, Berlin, Heidelberg. https://doi.org/10.1007/978-3-642-11762-6_1

[141] Hertzum, M. and Clemmensen, T. (2012) How Do Usability Professionals Construe Usability? International Journal of Human-Computer Studies, 70, 26-42.

[142] Rehm, M., Bee, N., Endrass, B., Wissner, M. and André, E. (2007) Too Close for Comfort? Adapting to the User's Cultural Background. Proceedings of the International Workshop on Human-Centered Multimedia, Augsburg, Bavaria, Germany, ACM Press, New York, 85-94.

[143] Nielsen, J., Bødker, M. and Vatrapu, R. (2010) Culture and (i)Literacy as Challenges to Scandinavian Cooperative Design. Proceedings of the 3rd International Conference on Intercultural Collaboration, Copenhagen, 19-20 August 2010, 271-274. https://doi.org/10.1145/1841853.1841905

[144] Cyr, D. and Trevor-Smith, H. (2004) Localization of Web Design: An Empirical Comparison of German, Japanese, and United States Web Site Characteristics. Journal of the American Society for Information Science and Technology, 55, 11991208. https://doi.org/10.1002/asi.20075

[145] Dormann, C. (2006) Cultural Representations in Web Design: Differences in Emotions and Values. In Mcewan, T., Benyon, D. and Gulliksen, J., Eds., People and Computers XIX-The Bigger Picture, London, 285-299. https://doi.org/10.1007/1-84628-249-7_18

[146] Smith, A., Dunckley, L., French, T., Minocha, S. and Chang, Y. (2004) A Process Model for Developing Usable Cross-Cultural Websites. Interacting with Computers, 16, 63-91. https://doi.org/10.1016/j.intcom.2003.11.005

[147] Maier, E., Mandl, T., Röse, K., Womser-Hacker, C. and Yetim, F. (2005) Internationalisierung von Informationssystemen: Kulturelle Aspekte der MenschMaschine-Interaktion. In Auinger, A., Ed., Workshops-Proceedings der 5. fachübergreifenden Konferenz Mensch und Computer 2005, Wien, 57-58.

[148] Röse, K., Zühlke, D. and Liu, L. (2001) Similarities and Dissimilarities of German and Chinese Users. In Johannsen, G., Ed., Preprints of 8 th IFAC/IFIP/IFORS/IEA Symposium on Analysis, Design, and Evaluation of Human-Machine Systems, Kassel, 24-29.

[149] House, R.J. and Aditya, R.N. (1997) The Social Scientific Study of Leadership: Quo Vadis? Journal of Management, 23, 409.

[150] House, R.J. (2004) Culture, Leadership, and Organizations: The Globe Study of 62 Societies. Sage, Thousand Oaks.

[151] Komischke, T., Mcgee, A., Wang, N. and Wissmann, K. (2003) Mobile Phone Usability and Cultural Dimensions: China, Germany \& USA. In: Mühlbach, L., Ed., Human Factors in Telecommunication, Proceedings of the 19th International Symposium on Human Factors in Telecommunication (HFT03), Berlin. 
[152] Rathje, S. (2003) Ist wenig kulturelles Verständnis besser als gar keins? - Problematik der Verwendung von Dimensionsmodellen zur Kulturbeschreibung. Interculture-Online IWK Uni Jena, 20.

[153] Hofstede, G. (2006) Culture's Consequences: Comparing Values, Behaviors, Institutions, and Organizations across Nations. Sage Publication, Thousand Oaks.

[154] Bryan, N.B., Mclean, E.R., Smits, S.J. and Burn, J. (1994) The Structure of Work Perceptions among Hong Kong and United States IS Professionals: A Multidimensional Scaling Test of the Hofstede Cultural Paradigm. Proceedings of the 1994 Computer Personnel Research Conference on Reinventing IS: Managing Information Technology in Changing Organizations: Managing Information Technology in Changing Organizations, Alexandria, 24-26 March 1994, 219-230. https://doi.org/10.1145/186281.186326

[155] Plocher, T., Patrick Rau, P.-L. and Choong, Y.-Y. (2012) Cross-Cultural Design. In Handbook of Human Factors and Ergonomics, John Wiley \& Sons, Inc., 162-191. https://doi.org/10.1002/9781118131350.ch6

[156] Clemmensen, T. (2009) A Framework for Thinking about the Maturity of Cultural Usability, Copenhagen Business School, C. B. S. Institut for Informatik I. N. F. Department of Informatics I. N. F.

[157] Clemmensen, T., Hertzum, M., Hornbæk, K., Shi, Q. and Yammiyavar, P. (2009) Cultural Cognition in Usability Evaluation. Interacting with Computers, 21, 212-220.

[158] Marcus, A. and Baumgartner, V.-J. (2004) A Practical Set of Culture Dimensions for Global User-Interface Development. In: Masood, M., Jones, S. and Rogers, B., Eds., Proceedings of 6 th Asia Pacific Conference on Computer Human Interaction (APCHI 2004), Rotorua, June 29-July 2 2004, 252-261.

https://doi.org/10.1007/978-3-540-27795-8_26

[159] Hampe-Neteler, W. (1994) Software-ergonomische Bewertung zwischen Arbeitsgestaltung und Softwareentwicklung. Lang, Frankfurt am Main.

[160] Nielsen, J. (2006) Usability Engineering. Kaufmann, Amsterdam.

[161] Eigenbrode, S.D., O'rourke, M., Wulfhorst, J.D., Althoff, D.M., Goldberg, C.S., Merrill, K., Morse, W., NIelsen-Pincus, M.A.X., Stephens, J., Winowiecki, L. and Bosque-Pérez, N.A. (2007) Employing Philosophical Dialogue in Collaborative Science. BioScience, 57, 55-64. https://doi.org/10.1641/B570109

[162] Heimgärtner, R., Windl, H. and Solanki, A. (2011) The Necessity of Personal Freedom to Increase HCI Design Quality. In: Marcus, A., Ed., Design, User Experience, and Usability, Theory, Methods, Tools and Practice (DUXU2011), Springer, Berlin, 62-68. https://doi.org/10.1007/978-3-642-21675-6_7

[163] Maguire, M. (2011) Guidelines on Website Design and Colour Selection for International Acceptance Design, User Experience, and Usability. In: Marcus, A., Ed., Theory, Methods, Tools and Practice, Springer Berlin/Heidelberg, 162-171.

[164] Biesterfeldt, J. and Capra, M. (2011) Leading International UX Research Projects Design, User Experience, and Usability. In: Marcus, A., Ed., Theory, Methods, Tools and Practice, Springer Berlin/Heidelberg, 368-377.

[165] Dong, J. and Salvendy, G. (1999) Designing Menus for the Chinese Population: Horizontal or Vertical? Behaviour and Information Technology, 18, 467-471.

[166] Dong, W. and Fu, W.-T. (2010) Toward a Cultural-Sensitive Image Tagging Interface. Proceedings of the 15 th International Conference on Intelligent User Interfaces, Hong Kong, 7-10 February 2010, 313-316.

https://doi.org/10.1145/1719970.1720019 
[167] Badre, A. (2000) The Effects of Cross Cultural Interface Design Orientation on World Wide Web User Performance. GVU Technical Report GIT-GVU-01.03, 130.

[168] Sun, X. and Shi, Q. (2007) Language Issues in Cross Cultural Usability Testing: A Pilot Study in China. Proceedings of the 2 nd International Conference on Usability and Internationalization, Global and Local User Interfaces, Springer-Verlag, Berlin, 274-284. https://doi.org/10.1007/978-3-540-73289-1_33

[169] Sun, H. (2012) The Case of Facebook Japan: Cross-Cultural Design in Postcolonial Conditions. Proceedings of the 30 th ACM International Conference on Design of Communication, Seattle, 3-5 October 2012, 367-368. https://doi.org/10.1145/2379057.2379130

[170] Zhang, Q., Chintakovid, T., Sun, X., Ge, Y. and Zhang, K. (2006) Saving Face or Sharing Personal Information? A Cross-Cultural Study on Knowledge Sharing. Journal of Information and Knowledge Management, 5, 73-80.

https://doi.org/10.1142/S0219649206001335

Submit or recommend next manuscript to SCIRP and we will provide best service for you:

Accepting pre-submission inquiries through Email, Facebook, LinkedIn, Twitter, etc. A wide selection of journals (inclusive of 9 subjects, more than 200 journals)

Providing 24-hour high-quality service

User-friendly online submission system

Fair and swift peer-review system

Efficient typesetting and proofreading procedure

Display of the result of downloads and visits, as well as the number of cited articles Maximum dissemination of your research work

Submit your manuscript at: http://papersubmission.scirp.org/

Or contact jcc@scirp.org 